\title{
Dopaminergic Regulation of Progesterone Receptors: Brain D5 Dopamine Receptors Mediate Induction of Lordosis by D1-Like Agonists in Rats
}

\author{
Ede Marie Apostolakis,, Janos Garai, ${ }^{1}$ Charles Fox, ${ }^{3}$ Carolyn L. Smith, ${ }^{1}$ Stanley J. Watson, ${ }^{4}$ James H. Clark, ${ }^{1}$ \\ and Bert W. O'Malley' \\ ${ }^{1}$ Department of Cell Biology, Baylor College of Medicine, Houston, Texas 77030, 2Department of Pathophysiology, \\ University Medical School of Pécs, Pécs, Hungary, ${ }^{3}$ Engineering Animation Inc., Ames, lowa 50010, and ${ }^{4}$ Mental Health \\ Research Institute, University of Michigan, Ann Arbor, Michigan 48109
}

To characterize the signaling pathway by which the neurotransmitter dopamine modulates progesterone receptor (PR) activation, the steroid-dependent behavior lordosis was used in estrogen-primed ovariectomized Sprague-Dawley rats with stereotaxic implanted third ventricle cannulas. Lordosis was observed in response to solicitous males in females after central administration of the D1-like agonist SKF38393 and three of its analogs (SKF77434, SKF75640, and SKF85174). In contrast, D1-like antagonist SCH23390 and D1-like/D2 repopulation inhibitor EEDQ blocked behavior inducible by the D1-like agonists. Further, antisense oligonucleotides to D5, but not D1, dopamine receptor mRNA suppressed reproductive behavior associated with D1-like stimulation. This finding provides strong evidence that dopaminergic modulation of lordosis is mediated by the novel D5 dopamine receptor. Although D1, but not D5, dopamine receptor mRNAs were detected in the ventromedial nucleus (VMN) by in situ hybridization, agonists microinjected into the VMN, but not into the arcuate nucleus or preoptic area, induced lordosis, suggesting the functional presence of D5 dopamine receptors in the VMN. Also in support, D5 receptor mRNA antisense microinjected into the VMN blocked the subsequent induction of lordosis by D1-like agonists. Finally, facilitation of sex behavior by D1-like agonists was blocked by the antiprogestin RU38486 and PR antisense oligonucleotide. Collectively, the data provide strong evidence for dopaminergic modulation of reproductive behavior through D5 dopamine receptor-mediated modulation of PR-dependent behavior in rat CNS.

Key words: steroid receptors; D5 dopamine receptors; lordosis; antisense oligonucleotides; progesterone; estrogen
In the female rat, the ovarian steroid hormone estrogen modulates the reproductive behavior lordosis (Pfaff and SchwartzGiblin, 1988). Estrogen effect on lordosis is mediated in part by steroid receptors in the estrogen-concentrating neurons located in the ventrolateral region of the hypothalamic ventromedial nucleus $(\mathrm{VMN})$. The major effect of estrogen on lordosis is thought to be mediated by progesterone receptors (PR), because (1) estrogen induces PR in the VMN, and (2) RU38486 and PR antisense oligonucleotide block the induction of lordosis by progesterone (P) (Pfaff and Schwartz-Giblin, 1988; McCarthy et al., 1993). Thus, the dependence of lordosis on estrogen and progestins can be used in vivo to probe cellular and molecular mechanisms for mammalian behavior.

As ligand-dependent nuclear transcription factors, steroid receptors alter the expression of specific genes or gene networks (Evans, 1988). However, the PR can be activated in vitro in a ligand-independent manner by the neurotransmitter dopamine (Tsai and O'Malley, 1994). Dopamine is thought to act selectively

Received Dec. 27, 1995; revised May 8, 1996; accepted May 13, 1996.

This work was supported by National Institutes of Health Grant HD-07857 (B.O.M.), National Institutes of Mental Health Grant P01 MH42251 (S.J.W.), and National Scientist Research Award Grant NRO6826 (E.M.A.). We thank K. E. Mayo (Northwestern University) for providing rat mRNA sequence, M. Caron (Duke University) for providing D5-expressing cell line, W. W. Vale (The Salk Institute) for providing GnRH, and SmithKline \& Beecham for providing SKF75670.

Preliminary results of this study have been published as an abstract at the Annual Meeting of the Endocrinology Society, June 15-19, 1994 (Anaheim, CA).

Correspondence should be addressed to Dr. Bert W. O'Malley, Department of Cell Biology, Baylor College of Medicine, One Baylor Plaza, Houston, TX 77030. Copyright (C) 1996 Society for Neuroscience $0270-6474 / 96 / 164823-12 \$ 05.00 / 0$ through D1-like and D2 receptors (Grierson et al., 1988). Centrally administered dopamine (Mani et al., 1994) and the D1-like agonist SKF38393 (Foreman and Moss, 1979) induce lordosis in rats primed with low doses $(5-10 \mu \mathrm{g})$ of estrogen. Further, the induction of lordosis by SKF38393 is blocked by the antiprogestin RU38486 and PR antisense oligos (Mani et al., 1994), suggesting a dependency of dopamine-induced lordosis on PR. Recently, a second D1-like receptor subtype, the D5 dopamine receptor, has been identified and localized in the male rat brain (Tiberi et al., 1991). To date, however, studies for D5 dopamine receptor localization in the female rat brain have not been reported. Moreover, currently available D1-like agonists fail to differentiate between the D1 and D5 dopamine receptor subtypes. Thus, the specific subtype of D1-like receptor involved in the dopaminergic induction of lordosis remains unknown. The purpose of the present study was to localize and characterize the membrane-bound receptor(s) by which dopaminergic agonists modulate(s) lordosis in highly receptive, estrogen-primed ovariectomized rats.

Preliminary results of this study have been published in abstract form at the Annual Meeting of the Endocrinology Society (Anaheim, CA).

\section{MATERIALS AND METHODS}

Synthesis of designed oligodeoxynucleotides and materials. Sense ( $5^{\prime}$ to $\left.3^{\prime}\right)$ and antisense ( $3^{\prime}$ to $\left.5^{\prime}\right)$-oligodeoxynucleotides were designed to symmetrically cover the translation initiation sites of the target sequences. Phosphorothiolated oligonucleotides were synthesized (SyntheCell, Columbia MA; National Biosciences, Plymouth, MN), lyophilized, and redissolved in sterile distilled water. Each animal served as its own control 
and was tested for lordosis immediately before oligonucleotide, and/or agonist treatments were administered. Another group of animals served as positive controls and included estradiol benzoate (EB)- and agonisttreated animals.

For the rat D1 dopamine receptor (Zhou et al., 1990), the sense sequence was 5'-CCA ATG GAT CCA CTG AAC GG-3', and the antisense sequence was 5'-CCG TTC AGT GGA TCC ATT GG-3'. A random sense sequence (5'-GTC CTA AGA GAC TGC TCA CG-3') also was designed for use as nonspecific control. Random sense sequences for D1 dopamine receptor showed no homology with the reported D1 or D5 receptor sequences in the Genbank. Sequences for D1 dopamine receptor showed no homology with the reported D5 dopamine receptor in the Genbank. In a separate experimental paradigm described below, the specificity of the oligonucleotide for D1 dopamine receptormediated events was demonstrated using a single dose (4 nM, i.c.v.) of oligos at $24 \mathrm{hr}$ after EB priming, e.g., $24 \mathrm{hr}$ before agonist treatment. This dose was most effective in inducing basal hyperactivity and blocking the induction of additional hyperactivity by a D1-like agonist in the experiments for specificity.

For the rat D5 dopamine receptor (Tiberi et al., 1991), the sense sequence was 5'-ACT CAG CGC GAC ATG CTG-3', and the antisense sequence was 5'-CAG CAT GTC GCG CTG AGT-3'. A random sense sequence (5'-CTA AAG AGC AGC TTG TTA-3') oligo was designed also for use as nonspecific control. Random sense sequences for D5 dopamine receptor showed no homology with the reported D5 or D1 dopamine receptor sequences in the Genbank. Sequences for D5 receptor showed no homology with the reported D1 dopamine receptor in the Genbank. Specificity of the D5 receptor oligonucleotides was tested in transient transfection studies described below and by in vivo use of a second antisense (5'-CAG TAC GAC GGA GGT-3'). The oligonucleotides (2 nM, i.c.v.) for D5 experiments were given once at $24 \mathrm{hr}$ after EB priming.

For the rat PR, the sense sequence was 5'-TG TTG TCC CCG CTC ATG AGC-3' (from the rat mRNA sequence kindly provided by K. E. Mayo, Northwestern University, Evanston, IL). The antisense sequence was 5'-GC TCA TGA GCG GGG ACA ACA-3'. These oligos (2.6 nm) were given concurrently with $\mathrm{EB} 48 \mathrm{hr}$ before agonist treatment and again $24 \mathrm{hr}$ later. This dose was highly effective in suppressing P-facilitated sexual behaviors (see Results) and is known to suppress EB-induced cellular PR concentration in the rat mediobasal hypothalamus (Mani et al., 1994).

Several selective dopaminergic agonists were used in the present studies. The D1-like agonists 1-phenyl-2,3,4,5-tetrahydro-benzazepine (SKF 38393) and $N$-allyl-benzazepine hydrochloride (SKF 77434), and the D1-like antagonist SCH23390 (Research Biochemicals, Natick, MA) were dissolved in sterile water. The D1 agonists 3-allyl-6-chloro-7,8-dihydroxy-1-2,3,4,5,tetrahydro-11-1-benzazepine (SKF85174), SKF82958, and SKF75670 were kindly provided by SmithKline \& Beecham (King of Prussia, PA) and also dissolved in water. The steroids $17 \beta$-estrogen benzoate (EB) and $\mathrm{P}$ (Sigma, St. Louis, MO), the antiprogestin RU38486 (Roussal-UCLAF, Paris, France), and the irreversible downregulator $N$-ethoxycarbonyl-2 ethoxy-1.2-dihydroquinoline (EEDQ) of D1-like and D2 repopulation were dissolved or suspended in sesame oil. For agonist control treatment in those animals cannulated in the arcuate nuclei (AN) or preoptic area (POA), gonadotropin-releasing hormone was kindly provided by W. W. Vale (The Salk Institute, La Jolla, CA) and suspended in sesame oil. All dopaminergic drugs were mixed not more than $1 \mathrm{hr}$ before intracerebroventricular administration and given between 1 and $2 \mathrm{hr}$ after lights on. Whenever possible, doses were based on published studies showing effective concentrations for desired effect; effective dose was then confirmed in the present study. Dose dependency was verified when appropriate.

Preparation of animals. Ovariectomized female rats (160-180 gm) were obtained from Sasco (Houston, TX), housed three per cage, and maintained on a 12:12 hr light/dark cycle (lights on at 0700 CST) with rat chow and water in excess ad libitum. After acclimation (5-7 d), animals were primed with EB (100 $\mu$ g, s.c., at $-44 \mathrm{hr})$, then treated with P (100 ng, s.c., at $0 \mathrm{hr}$ ), and screened for $10 \mathrm{~min}$ at $2-4 \mathrm{hr}$ for receptive sex behavior to a series of two sexually active males housed individually in $50 \times 45 \times 24$ $\mathrm{cm}$ polystyrene arenas. Females displaying lordosis underwent stereotaxic implantation of third ventricle cannula guides (26 gauge) (Plastics One, Roanoke, VA) as described previously (Mani et al., 1994). To avoid cannula disruption by cagemates, females were housed individually after surgery under conditions described above and screened after $7 \mathrm{~d}$ to verify the presence of P-induced (50 ng, i.c.v., 1-2 hr after lights on) lordosis 48 hr after EB priming (50 $\mu$ g, s.c.). Only those cannulated females exhibiting high levels of proceptive and receptive behaviors, measured and expressed as lordosis quotient (LQ), in response to mounting by sexually solicitous males were used in experiments.

Behavioral testing lordosis in female rats. For each experiment, females were randomly assigned identification numbers after experimental treatment and at 1-4 hr later randomly tested during the light cycle for lordosis (LQ) with a series of four males for $5 \mathrm{~min}$ each. Prospective scoring was done by individuals blind to individual animal treatment. Tests for intertester and intratester reliability were conducted on a regular basis. Briefly, LQ was calculated as percent lordosis (immobile dorsiflexion of the female vertebral column with head at $45^{\circ}$ angle from floor and perineal elevation preceded by flank contact with the male) per total mounts $\times 100$. To provide maximal quantification and description, behavioral scores were assigned $(0=$ no dorsiflexion; $1=$ slight dorsiflexion, some head elevation, back parallel to floor; $2=$ moderate dorsiflexion with some leg extension from crouch position; $3=$ full dorsiflexion). Only scores of 2 and 3 were judged positive for lordosis. Also noted were such receptive behaviors as acceptance and rejection. Finally, proceptive behaviors such as hopping, darting, ear wiggling, and approaching were recorded. To allow for females to act as their own controls, testing was conducted immediately before experimental treatment. All rats were tested before EB priming and excluded if they displayed false-positive responses (20\% LQ).

Location studies. For those rats participating in the location studies, double cannulae were implanted in the VMN (26 gauge with $1.5 \mathrm{~mm}$ center to center of cannulae) and $\mathrm{AN}$ (26 gauge, $1.0 \mathrm{~mm}$ between cannulae) and POA (26 gauge, $1.5 \mathrm{~mm}$ between cannulae) according to the stereotaxic atlas of Paxinos and Watson (1988). For cannulae placement, the incisor bar was lowered $3.3 \mathrm{~mm}$ below horizontal zero to achieve a flat-skull position. Coordinates for VMN placement were antero-posterior, bregma, $-2.56 \mathrm{~mm}$; lateral, $+5 \mathrm{~mm}$; dorso-ventral, $-9.2 \mathrm{~mm}$. For AN and POA placement, the antero-posterior coordinates were $-3.30 \mathrm{~mm}$ and $-0.30 \mathrm{~mm}$, respectively. Dorso-ventral coordinates were $-10.3 \mathrm{~mm}$ and $-8.3 \mathrm{~mm}$ for AN and POA, respectively. At the end of experiments, rats were anesthetized and decapitated. The brains were removed, fixed in $4 \%$ paraformaldehyde, rinsed twice $(0.1 \mathrm{M} \mathrm{PBS}, \mathrm{pH}$ 7.4), and cryoprotected by immersion in $30 \%(\mathrm{w} / \mathrm{v})$ sucrose. Tissue blocks were mounted in OCT (Fisher Scientific, Houston, TX) frozen with dry ice, and stored at $-70 \mathrm{C}$. Hypothalamic sections $(10-25 \mu \mathrm{m})$ were cut thaw mounted and fixed on slides (2\% glutaraldehyde/1\% formaldehyde in $0.1 \mathrm{M}$ PBS, pH 7.4). After overnight drying at room temperature and progressive rehydration, sections were stained with cresyl violet followed by progressive dehydration $(70,95$, and $100 \% \mathrm{EtOH} \times 2)$, clarified with xylene, and slip covered for examination under a microscope. The localization of the cannula tips was determined using the atlas of Paxinos and Watson (1988). Behavioral data were collated and analyzed according to tip location. Only data from animals with both tips in nuclei are presented.

In situ hybridization study and probe preparation. Tissue preparation and in situ hybridization were performed as described previously (Fox et al., 1993), using two radiolabeled RNA probes described previously (Fox et al., 1994). Hybridization was performed on sequential sections that contained the VMN and AN. The most rostral sections showed the supraoptic decussation, whereas the most caudal included the mammillary nuclei. The D1 dopamine receptor cRNA probe was transcribed from a $530 \mathrm{bp}$ $B a m \mathrm{HI} / E c o \mathrm{RI}$ fragment of a rat D1 receptor cDNA. This probe corresponds to transmembrane domains III-VI (bp 383-843). A 650 bp riboprobe complementary to the rat D5 dopamine receptor mRNA was generated from a partial D5 receptor cDNA corresponding to transmembrane domains II-VI subcloned into the Sall/EcoRI sites of pGEM $3 Z$ (Promega, Madison, WI), encoding transmembrane domains II-VI of the rat D5 dopamine receptor gene. Controls for the mRNA probes have been described previously (Fox et al., 1994). No hybrid signal should be observed in adjacent sense probe-hybridization sections. RNase controls also were performed in which adjacent sections were treated with RNase A $(200 \mu \mathrm{g} / \mathrm{ml})$ for $30 \mathrm{~min}$ at $37^{\circ} \mathrm{C}$ before hybridization. Again, no hybridization signal should be observed.

Studies for specificity of D1 dopamine receptor oligonucleotide specificity. Dopaminergic receptors in striatum and nucleus accumbens mediate levels of basal motor activity. Importantly, phenotypic behavior in targeted D1 mutant mice relative to their wild-type littermates include basal hyperactivity and failure of SKF82958 challenge to maximally enhance motor hyperactivity (Xu et al., 1994). Hence, the absence of functional D1 dopamine receptors is associated with basal hyperactivity and an 
absence of additional enhancement in motor activity after D1-like stimulation. To determine the specificity of the D1 oligonucleotides for D1 receptor-mediated events, motor activity levels were assessed via intraaccumbal microinjection of oligonucleotides $(0.5 \mu \mathrm{l}$ of $4 \mathrm{nM} / \mu \mathrm{l}$ per cannula) and D1-like agonist challenge. Double cannulae (26 gauge, 2.5 $\mathrm{mm}$ center to center) implanted into the nucleus accumbens by stereotaxic placement using coordinates according to Paxinos and Watson (1988) (Dreher and Jackson, 1989). Seven days later, rats were numbered randomly and tested in clear Plexiglas cages $(44 \times 35 \times 20 \mathrm{~cm})$ during the light phase. Beams were placed at equal intervals of $11 \mathrm{~cm}$ along length and $4 \mathrm{~cm}$ along height. All sessions were tape recorded, and number of crossings were scored for each animal by an examiner blind to treatment. Horizontal crossings were considered ambulation, and vertical breaks were considered rearing. The data represent horizontal, but not vertical, breaks. For each study, motor activity was determined for two sessions per day over a $3 \mathrm{~d}$ period. The first session was for habituation and lasted for $30 \mathrm{~min}$ after the animal was placed in the cage. The second session was two hr later when behavior was evaluated for persistence of motor activity and was scored over a $1 \mathrm{hr}$ interval. Rearing, sniffing, and grooming behavior also was tallied for $15 \mathrm{sec}$ out of every five min to ascertain any stereotypic behavior that may account for the motor activity. After assessing basal motor activity on day 0 , animals were administered oligos (2-4 nM) into the nucleus accumbens and tested $24 \mathrm{hr}$ later for the influence of oligonucleotides on habituation and persistence of motor activity. Animals treated with antisense oligonucleotides should display basal hyperactivity as a result of disruption of functional D1 dopamine receptors. Random sense-treated animals should exhibit activity levels comparable to pretreatment levels if there is no disruption of functional receptor and no nonspecific toxicity. For the effect of challenge by D1-like agonist, animals received SKF82958 (2.42 mg/kg i.p.) $48 \mathrm{hr}$ after oligo treatment. When compared with activity levels after antisense treatment only, there should be no augmentation of basal motor activity after challenge in those animals who received D1 antisense pretreatment if the D1 antisense disrupted functional D1 dopamine receptors. In contrast, animals receiving random sense oligo + challenge should display hyperactivity if D1 receptors are intact and functional. All sessions were replicated starting $14 \mathrm{~d}$ later. Cannulae position was verified as described above, and the data presented are from those animals with tips in the nucleus accumbens.

Studies for D5 dopamine receptor oligonucleotide specificity. Using another clearly defined experimental system, the specificity of D5 dopamine receptor oligonucleotides was assessed in transient transfection experiments in mouse $\mathrm{L}(\mathrm{tk}-)$ fibroblast cell line that stably expresses rat D5, but not D1, dopamine receptors (kindly provided by Dr. Marc G. Caron, Duke University). Cells were routinely grown in DMEM supplemented with $10 \% \mathrm{FCS}$, penicillin $(100 \mathrm{U} / \mathrm{ml})$, streptomycin $(100 \mu \mathrm{g} / \mathrm{ml})$, and $\mathrm{G} 418(0.5 \mathrm{mg} / \mathrm{ml})$. Twenty four hours before transfection, $2.5 \times 10^{-5}$ cells per well were plated in a six-well culture dish in phenol red-free DMEM containing 5\% charcoal-stripped FBS. Cells were then transferred to serum-free DMEM and infected with a variable amount of antisense or random sense D5 oligonucleotides $(0-0.83 \mathrm{nmol} /$ well $)$ in the presence of $12.5 \mathrm{ng} /$ well rat estrogen receptor (ER) expression vector (pJ3ratER) and $125 \mathrm{ng} /$ well of a synthetic ER-responsive target gene (ERE-e1b-CAT). The ERE-e1b-CAT gene consists of the vitellogenin A2 estrogen response element linked upstream of the e1b TATA box and chloramphenicol acetyl transferase (CAT) reporter gene. A modified adenoviral system described by Cristiano et al. (1993) was used for delivery. Briefly, $\mathrm{CsCl}$ gradient-purified, replication-deficient adenovirus (d1312) was conjugated to poly-L-lysine using $16 \mu \mathrm{M}$ 1-ethyl-3-(3-dimethylaminopropyl)carbodiimide. Subsequently, lysine-conjugated adenovirus was sequentially incubated with the DNA of interest, followed by a 200 -fold molar excess (lysine:DNA) of poly-L-lysine resulting in a DNA-adenovirus complex efficiently internalized by target cells. This complex was used to infect cells at a multiplicity of infection of 1000:1. Two hours after infection, medium was replaced with phenol red-free DMEM containing $5 \%$ stripped FBS. Six hours thereafter, cells were challenged with vehicle (ethanol) or the D1-like agonist SKF82958 (10 mm) for $16 \mathrm{hr}$. Cells were harvested, and CAT activity was determined as described previously (Smith et al., 1993). Specifically, D5 dopamine receptor mRNA antisense oligonucleotide inhibition of gene expression was calculated as [1 (percent of CAT activity expressed in D5 antisense-treated cells divided by the CAT activity measured in D5 random sense-treated cells)]. Studies were performed in duplicate.

Statistics. When animals served as their own controls, the significance of change in reproductive or motor behavior was assessed by two-way
ANOVA with repeated measures ( $\mathrm{p} \leq 0.05$ significant). Duncan's multiple range test was used for individual comparisons. When groups of animals were compared, one-way ANOVA, followed by the MannWhitney $U$ test and Student's $t$ test, was used. In the lordosis studies, the occurrence of proceptive behavior was altered in parallel with the lordotic activity and have not been statistically reported here. In the locomotor studies, the occurrence of sniffing, rearing, and grooming was consistent throughout all sessions regardless of treatment.

\section{RESULTS}

\section{General behavior responses to EB}

Animals receiving EB (subcutaneously) and P (subcutaneously or introcerebroventricularly) consistently exhibited high levels of proceptive (ear wiggling, hopping, and darting) and receptive (lordosis) behaviors in response to male mounting during the light cycle. Because excessively high doses of estrogen can induce lordosis in the absence of P (Pfaff and Schwartz-Giblin, 1988) and because the intent of the present study was to determine the effects of various drugs and oligos in highly receptive females, an EB-priming dose of $50 \mu \mathrm{g}$ was chosen after dose-response experiments assessing false-positive sexual behavior of EB-only treated rats. At $\leq 50 \mu \mathrm{g}$, only an occasional female exhibited sporadic receptive behavior $48 \mathrm{hr}$ after priming. As expected, higher priming doses of EB $(100 \mu \mathrm{g})$ were characterized by more frequent displays of receptive behavior with LQs exceeding $20 \%$ in some animals. When given intracerebroventricular P, the LQs of all EB-primed $(50 \mu \mathrm{g})$ females exceeded $90 \%$. Thus, rats administered a subcutaneous EB-priming dose of $50 \mu \mathrm{g}$ were highly receptive and could be used as their own controls for false-positive responses and for experimental effects when behavioral testing for control was conducted before administration of experimental drugs.

The high EB-priming dose used in this study afforded the opportunity for decreasing intracerebroventricular P dose toward more physiological concentrations. For positive controls and screening for false-negative animals, an intracerebroventricular $\mathrm{P}$ dose of $50 \mathrm{ng}$ was chosen, because this dose was associated with the exhibition of proceptive and receptive behaviors comparable with those receiving lower EB (10 $\mu$ g, s.c.) and higher P (2 mg, s.c.) doses. For all experiments, the data from animals treated with EB only that exhibited an LQ of $20 \%$ or above before experimental treatment ( $8 \pm 2 \%$ of all animals) were excluded from analysis. Administration of vehicle alone failed to facilitate lordosis.

\section{Dose response to D1-like dopamine agonists}

It has already been demonstrated that the D1-like agonist SKF38393, but not its vehicle, induces lordosis in rats primed with EB $(5-10 \mu \mathrm{g})$ (Foreman and Moss, 1979). To characterize the ability of D1-like agonists to induce lordosis in highly receptive female rats, dose responses to the selective D1-like agonists SKF77434, SKF75640, and SKF85174 were assessed and compared with those of animals receiving SKF38393. All four D1-like agonists were associated with the exhibition of proceptive and receptive (lordosis) behaviors (Fig. 1, lanes 6, 7, 10-12, 15-17, 20). Lordosis intensities for animals treated with optimal doses of all the SKF compounds were statistically comparable with those of females receiving EB and $\mathrm{P}$. In the absence of EB, treatment with optimal doses of D1-like agonists failed to result in lordosis responses (Fig. 1, lanes 3, 8, 13, 18). 


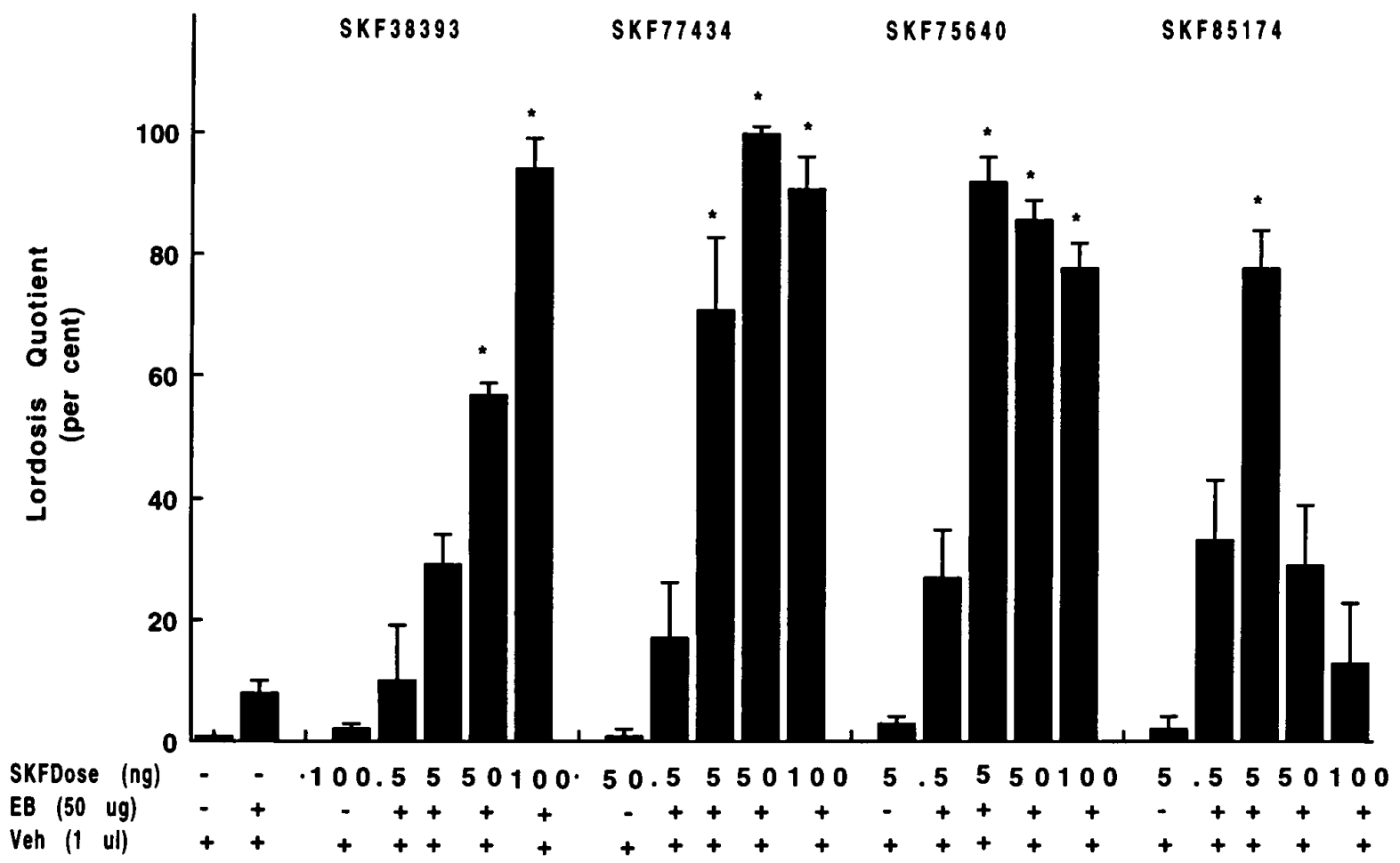

Figure 1. Ability of selective D1-like dopaminergic agonists to mediate reproductive behavior in ovariectomized rats with indwelling third ventricle cannulae. Microinjections of four selective D1-like agonists facilitated sex behavior in highly receptive rats primed with EB. Each experiment was repeated at least twice. The results are expressed as LQ (defined as percent of positive lordosis responses divided by number of mounts by a series of 4 male rats). Bars represent mean LQ $\pm \mathrm{SEM}$. Asterisks indicate a significant increase in LQ compared with the pretreatment response of the same rats $1 \mathrm{hr}$ before D1-like agonist treatment (ANOVA, $p \leq 0.01$ ) and/or the response in control females (one-way ANOVA followed by Mann-Whitney $U$ test, $p \leq 0.01$ ). Females were excluded if LQ exceeded $20 \%$ during tests for false-positive responses before receiving EB and for EB effect before agonist treatment. In another group of control rats, vehicle $(0.1 \mathrm{ml}$, i.c.v. $)$ was administered as a control for false results.

\section{Inhibition of behavioral responses by D1-like antagonists}

Selective D1-like blockade and inhibition of dopamine receptor repopulation suppressed the induction of lordosis by D1-like agonist stimulation (Fig. 2). When animals were pretreated for 1 hr with the D1-like antagonist SCH23390, lordosis responses after microinjections of SKF38393 were blocked in a dose-dependent manner (Fig. 2, lane 7) (most effective dose). Likewise, animals pretreated for $24 \mathrm{hr}$ with the irreversible D1-like/D2 antagonist EEDQ consistently failed to display receptive behavior after the dopaminergic agonist was administered (Fig. 2, lane 10). Hopping, darting, and ear wiggling also were inhibited by both antagonists, whereas rejection behaviors were common. In the presence or absence of EB, neither SCH23390 nor EEDQ facilitated the appearance of lordosis (Fig. 2, lanes 6, 9 for EB, and lanes 3, 8 for no EB pretreatment). Likewise, neither vehicle nor EB induced response (Fig. 2, lanes 1, 2).

\section{D1 and D5 dopamine receptor oligodeoxynucleotides, behavior, and transcription}

Antisense oligonucleotide to rat D5, but not D1 dopamine receptor mRNA, effectively suppressed SKF induction of receptive (LQ) behavior (Fig. 3). Oligos were administered intracerebroventricularly $24 \mathrm{hr}$ before agonist treatment. Commonly, females pretreated with antisense oligos to D5 (2 nM), but not D1 (2-4 $\mathrm{nM}$ ), dopamine receptor mRNA aggressively rejected male solicitation (Fig. 3, lanes 11, 15, 19 for D5 AS, lane 7 for D1 AS). In contrast, females administered either random sense to D5 receptor mRNA (Fig. 3, lanes 9, 13, 17) or random sense or antisense to D1 receptor mRNA (Fig. 3, lanes 5, 7) exhibited high levels of receptive and proceptive behaviors when given D1-like agonists. No significant effect on reproductive behavior was observed for random sense and antisense oligos in the presence of only EB (Fig. 3, lanes 4, 6, 8, 10, 12, 14, 16, 18). For oligos to D1 dopamine receptor mRNA, no untoward effect was noted in animals. In contrast, a high dose (4 nM) of D5 antisense was associated with the death of several animals within $48 \mathrm{hr}$ of oligo treatment. A lower dose (1 nM) of D5 antisense was characterized by irregular displays of lordosis and frequent, aggressive rejection behaviors when challenged with D1-like agonists.

Specificity for D1 and D5 dopamine receptor oligonucleotides were shown in separate experiments. To ascertain the effect of D1 dopamine receptor mRNA oligos, motor activity was assessed immediately before and $24 \mathrm{hr}$ after intra-accumbal microinjection of antisense (2-4 nM), random sense (4 nM), and/or vehicle as described previously. For all animals receiving antisense to the D1 receptor mRNA, levels of basal motor activity were higher compared with pretreatment levels (Fig. 4 A, lanes 5 vs 4 , and 8 vs 7 ) (ANOVA, $p<0.05$ ). No difference in rearing, sniffing, and grooming was noted. Behavior consistent with amphetamine, serotonin syndrome, or stereotypy was not observed. In random sense-treated and vehicle-treated animals, locomotor activity levels were similar to pretreatment basal activity levels (Fig. 4A, lane 2 vs lane 1). When the persistent effect of D1 receptor oligos was tested after $48 \mathrm{hr}$, animals pretreated with antisense oligo (4 nM) failed to display additional augmentation of hyperactivity after SKF82958 challenge (Fig. 4A, lane 9 vs lane 8 ). In contrast, it was 


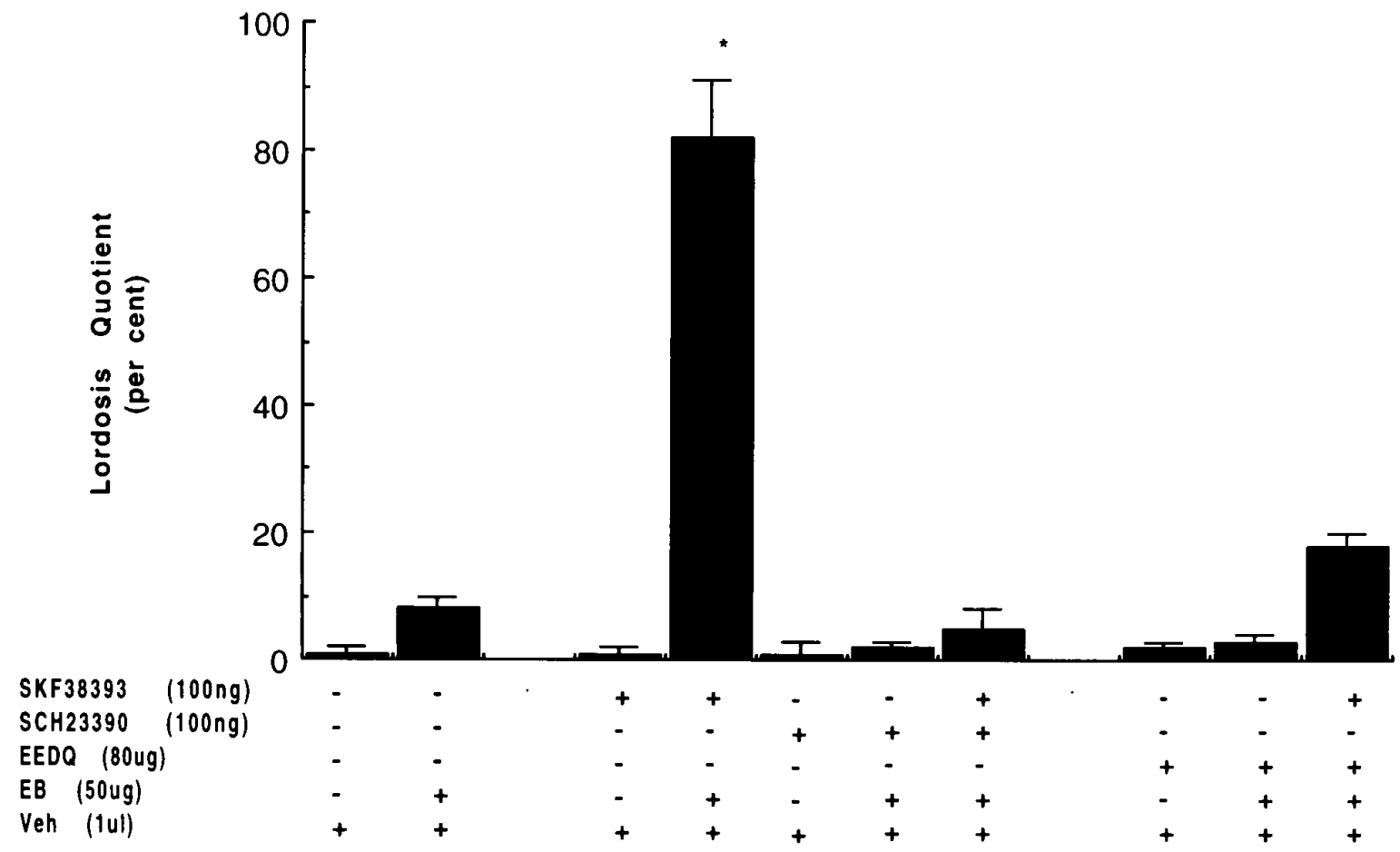

Figure 2. Inhibition of SKF-induced lordosis behavior by selective D1-like antagonists. Chronically cannulated rats primed with EB were given microinjections of the D1-like antagonist SCH23390 $1 \mathrm{hr}$ before or the irreversible D1-like/D2 antagonist EEDQ $24 \mathrm{hr}$ before challenge with SKF38393. The animals were screened for nonspecific effect of antagonist before agonist challenge and analyzed as described in Figure 1 and in Materials and Methods.

only after SKF challenge that hyperactivity was displayed by animals treated with random sense (Fig. $4 A$, lane 3 vs lane 2).

Agonists for D1-like dopamine receptors activate the PR and ER in a steroid ligand-independent manner in transient transfection assays (Smith et al., 1993; Tsai and O’Malley, 1994). However, expression vectors for rat PR are currently unavailable. Therefore, to determine whether antisense oligonucleotide to D5 receptor specifically inhibit a D5 receptor-mediated event, the ability of D5 antisense oligonucleotides relative to their random sense counterparts to block SKF82958 activation of ERdependent target gene transcription was examined. Both a rat ER expression vector and a synthetic target gene, ERE-e1b-CAT, were delivered to cultured mouse $\mathrm{L}(\mathrm{tk}-)$ fibroblast cells expressing D5, but not D1, dopamine receptors. In the absence of any oligonucleotides, SKF82958 induced a 24-fold induction of CAT gene expression over basal (vehicle) levels. When oligonucleotides were delivered to cells, the D5 antisense inhibited the ability of SKF82958 to activate receptor-dependent transcription in a dose-dependent manner (Fig. $4 B$ ). At the highest dose used in this study (0.83 nmol/well) (Fig. 4B, lane 4$)$, the antisense blocked $85 \%$ of the SKF82958-activated, ER-dependent transcription. Random sense D5 oligonucleotides also reduced CAT gene expression, but to a much lesser extent than the antisense oligonucleotides, an effect likely attributable to nonspecific toxic effects of phosphorothioated oligonucleotides (Ehlrich et al., 1994).

\section{Inhibition of behavioral responses by RU38486 and AS to PRa mRNA}

Sexual behavior failed to be facilitated by D1-like agonists in the presence of antisense to PRa mRNA or the antiprogestin RU38486 (Fig. 5). In EB-primed rats, pretreatment with RU38486 suppressed SKF38393-facilitated lordosis (Fig. 5, lane
8). As with RU38486, the effect of SKF38393, SKF75670, or SKF85174 on receptive behavior was seriously attenuated when phosphorothioated antisense to PRa mRNA was given as described above (Fig. 5, lanes 14, 19, 24). In contrast, animals receiving sense oligo exhibited high levels of receptive behavior after intracerebroventricular challenge with SKF38393, SKF75670, or SKF85174 (Fig. 5, lanes 11, 17, 22). In these animals receiving EB-priming and sense or antisense treatment, displays of lordosis and proceptive behaviors were absent $1 \mathrm{hr}$ before the administration of SKF38393 (Fig. 5, lanes 9, 16, 21 for sense, and lanes 12, 18, 23 for antisense). Control animals receiving EB + RU38486 displayed sporadic lordosis responses (Fig. 5, lane 4). As with all oligos, neither vehicle nor RU38486 in the absence of EB was associated with receptive behavior (Fig. 5, lanes 1, 2). Both antisense oligo and RU38486 suppressed the effect of $P$ on sex behavior (Fig. 5, lane 3 vs lanes 5, 13), whereas sense oligo had no effect on P-inducible behavior (Fig. 5, lane 10).

\section{Localization of dopaminergic activity and behavior by intranuclear injections}

Microinjections of dopaminergic agonists (SKF38393, SKF75640, SKF85174) in the VMN facilitated receptive behavior in EBprimed rats (Fig. $6 A$, lanes $5,11,15$ ). In contrast, $24 \mathrm{hr}$ pretreatment with D5 dopamine receptor mRNA antisense by direct VMN microinjections suppressed SKF-induced receptive behavior (Fig. 6A, lanes 9, 13, 19). As with third ventricle injections, VMN microinjections of sense oligonucleotide had no effect on the induction of receptive behavior when the VMN was challenged with D1-like agonists (Fig. 6A, lanes 7, 12, 16). Both antisense- and sense-treated females failed to display sex behaviors $1 \mathrm{hr}$ before SKF38393 treatment (Fig. 6A, lanes 6, 8, 11, 15). During control experiments, all of these animals responded with 


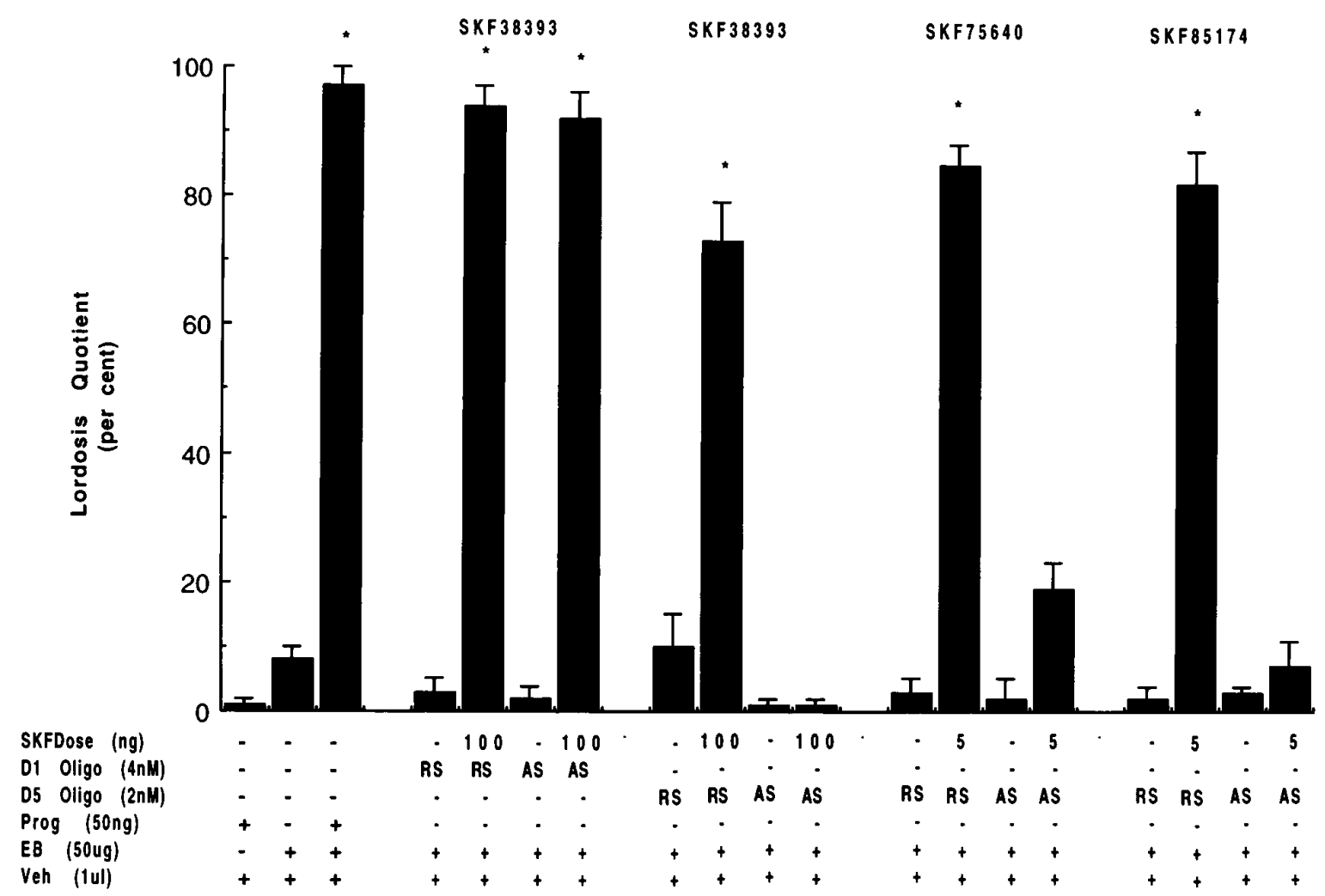

Figure 3. Inhibition of SKF-facilitated sex behavior by phosphorothiolated antisense $(A S)$ oligonucleotides to D5, but not D1, dopamine receptor mRNA. Oligonucleotides ( 2 and $4 \mathrm{~nm}$ for D5 and D1 receptors, respectively) were microinjected into indwelling third cerebroventricular cannulae 24 hr after EB priming. Twenty-four hours later, animals were tested for the behavioral effect of EB + oligonucleotide and then challenged with D1-like agonists. Random sense $(R S)$ oligos were given to another group of rats as a control for nonspecific oligo effect.

LQs above $90 \%$ to $\mathrm{P}$ challenge (Fig. 6A, lane 3). In another control group of animals with third ventricle cannulas that served to verify the effectiveness of SKF38393 on the day of intranuclear injections, LQs were above $85 \%$ (data not shown).

For both AN and POA microinjections, SKF38393 failed to induce lordosis responses (Fig. 6B, lanes 21, 25). Excessive displays of aggression were common for females receiving SKF38393 in the POA and were absent before SKF treatment. Aggressive behaviors were less apparent at $4 \mathrm{hr}$, but vocalizations and rejection remained excessive. Rejection behavior was common when SKF38393 was administered in the AN. Intracerebral nuclei cannulation did not decrease the ability of ovariectomized females to exhibit proceptive or receptive responses when treated with appropriate agonists (Fig. 6B, lanes 20, 22, 23).

\section{Anatomical distribution of D1 and D5 dopamine receptor mRNAs and in situ hybridization}

The in situ hybridization studies show that D1 dopamine receptor mRNA are densely distributed throughout the VMN of EBprimed ovariectomized rats as well as the VMN of male rats (Fig. $7 D 1, A)$. The area of highest density appeared to be more lateral than medial. In comparison, D5 receptor mRNA was not detected in the VMN of either the EB-primed ovariectomized rat nor the male rat (Fig. 7D5, B). Slides dipped in photoemulsion (NTB2) and exposed for several weeks until background was unacceptably high did not reveal any additional positive cells. As expected from previous studies for distribution of mRNA (Tiberi et al., 1991), D5 dopamine receptor mRNA was distributed densely throughout the reuniens thalamic nucleus $(R e)$, endopiriform nucleus $(E n)$, and perifascicular thalamic nucleus. On adjacent slides used for methodological controls, no specific hybridization was observed in any of the brain areas identified after either RNase pretreatment $\left(30 \mathrm{~min}, 37^{\circ} \mathrm{C}\right)$, "sense"-strand hybridization or not treated (data not shown).

\section{DISCUSSION}

The present study demonstrates that steroid-dependent behavior can be potentiated by activation of dopaminergic pathways through the membrane-bound D5 dopamine receptor in estrogenprimed, ovariectomized rats. This conclusion is supported by the finding that four D1-like agonists facilitated receptive behavior. In contrast, pretreatment with D1-like antagonist or D1-like/D2 receptor repopulation inhibition blocked behavioral facilitation by D1-like challenge with SKF38393. Importantly, antisense oligonucleotides to D5, but not D1, dopamine receptor mRNA suppressed induction of receptive behavior when animals were challenged with the D1-like agonists SKF38393, SKF75640 ,and SKF85174. Further, potentiation of reproductive behavior by dopaminergic agonists was dependent on $\mathrm{PR}$, because pretreatment with either antiprogestin or PR antisense oligonucleotides also blocked the effect of D1-like agonists. Finally, the effects of D1-like agonists were selective for the VMN, because agonist microinjections into the $\mathrm{VMN}$, but not $\mathrm{AR}$ or POA, facilitated induction of proceptivity and receptivity. Further, intranuclear D5 dopamine receptor mRNA antisense and D1-like receptor antagonism or repopulation blockade suppressed facilitation of sex behavior by D1-like agonists. Collectively, the data provide strong evidence for dopaminergic modulation of reproductive behavior 


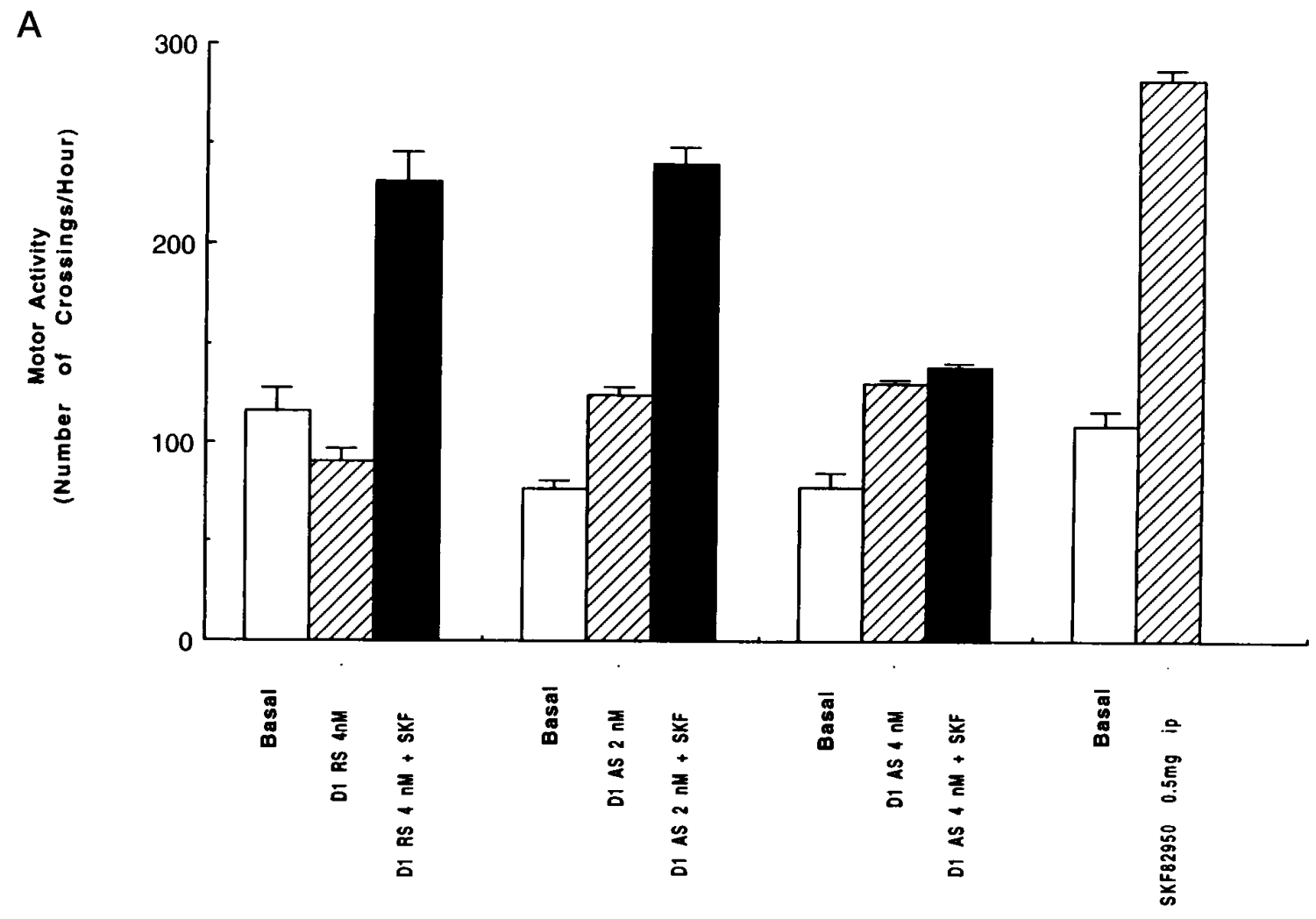

B

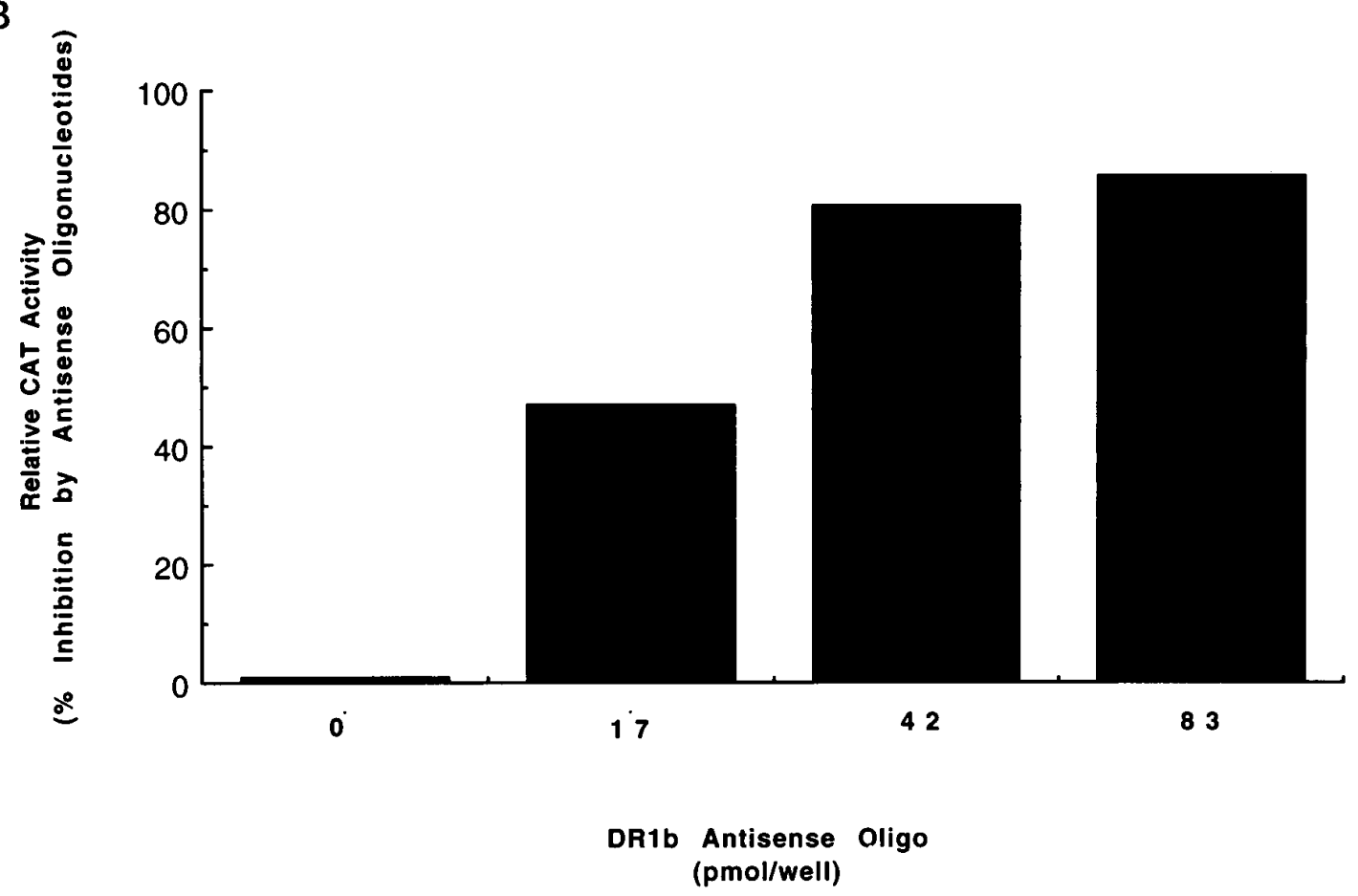

Figure 4. Specific effects of antisense $(A S)$ and sense $(S)$ oligonucleotides to D1 $(A)$ and D5 $(B)$ dopamine receptor mRNAs. $A$, Nuclear accumbens treatment with D1 antisense increases basal motor activity and blocks the induction of additional hyperactivity after SKF82958. A behavioral paradigm known for its D1 dopamine receptor specificity in targeted mutagenic mice $(n=40)$ was used as in Materials and Methods. Data are replicates of two experiments. B, Treatment with increasing levels of D5 antisense increases the inhibition of D1-like agonist-stimulated CAT gene expression. Mouse $\mathrm{L}(\mathrm{tk}-)$ fibroblast cells stably expressing D5 dopamine receptors were transiently transfected with the rat ER expression vector and the ERE-elb-CAT reporter gene in the presence of increasing amounts (17-83 pmol/well) of antisense or random sense oligonucleotides to D5 dopamine receptors mRNA and subsequently treated with $10 \mu \mathrm{M}$ SKF82958. Data are calculated as [1 - (\%CAT activity in antisense oligo-treated cells/CAT activity in random sense cells)]. The presented results are the average of two experiments, each performed in duplicate. Values between experiments varied by $<10 \%$. 


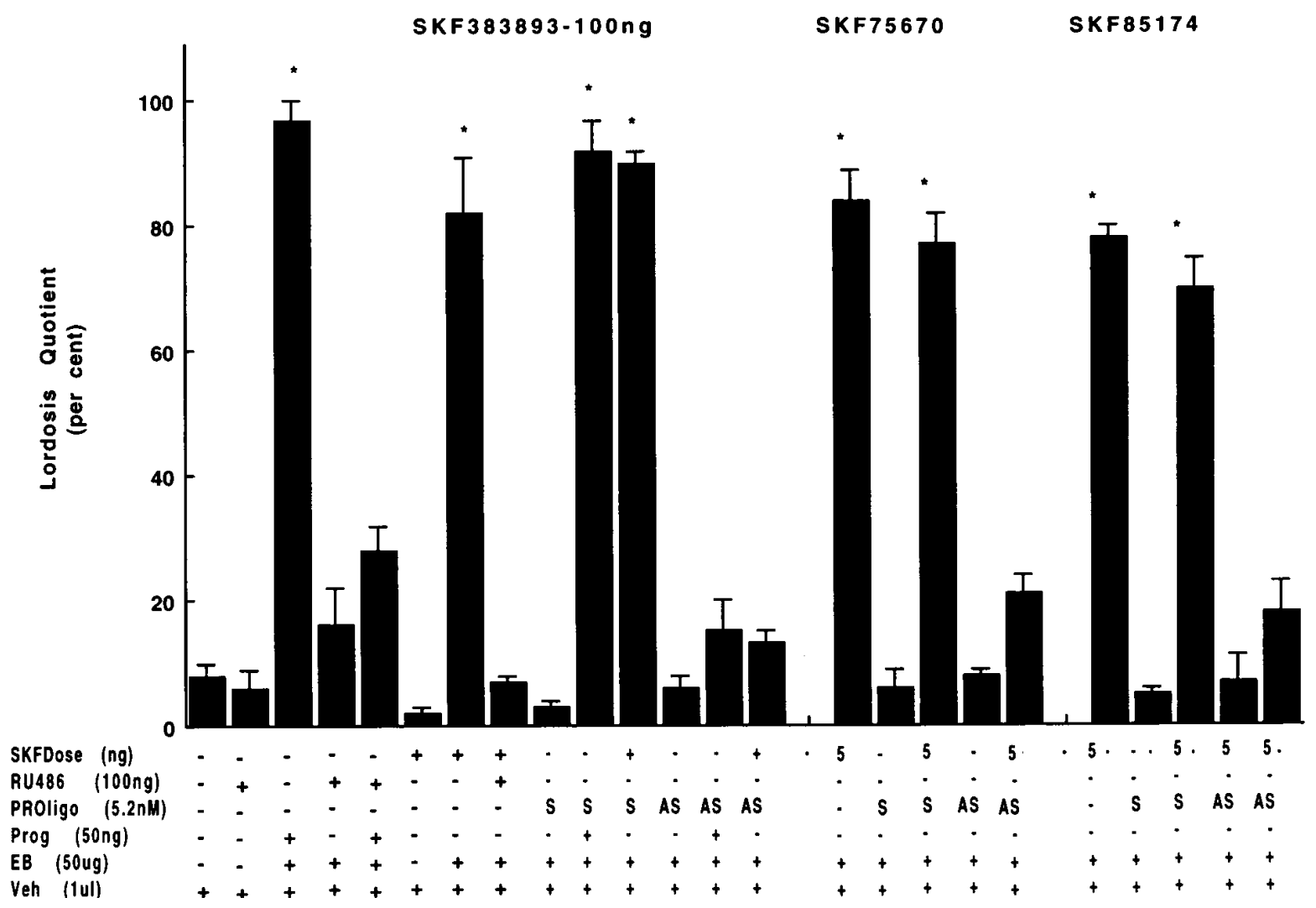

Figure 5. Inhibition of SKF-induced lordosis response by antisense oligonucleotides to PRa mRNA and the antiprogestin RU38486 (RU486). Rats were administered RU38486 and challenged with D1-like agonist $1 \mathrm{hr}$ later. In another group, oligonucleotides (2.6 nM, i.c.v.) were administered concurrently with EB and $24 \mathrm{hr}$ later. At $48 \mathrm{hr}$ after EB priming, animals received intracerebroventricular SKF challenge and were tested for behaviors as described in Materials and Methods.

through D5 dopamine receptor-linked second messenger pathways in a PR-dependent manner.

The present results support previous studies (Everitt et al., 1975; Everitt and Fuxe, 1977; Foreman and Moss, 1979; Grierson et al., 1988; Mani et al., 1994) indicating that third ventricle administration of dopamine or the selective D1-like agonist SKF38393 facilitates receptivity and extends previous findings to three analogs of SKF38393. In vitro, the four D1-like agonists used in this study possess different relative efficacies [compared with dopamine $(100 \mathrm{~mm})$ ] for stimulating adenylyl cyclase in rat striatal tissue (Andersen and Jansen, 1990; Undie and Friedman, 1992). The relative efficacies of SKF38393 and SKF77434 for adenylyl activity are similar (45-48\% of the maximum dopamine activity), whereas the efficacy of SKF75670 is at $14-23 \%$ and SKF85174 at 86\% (Andersen and Jansen, 1990; Undie and Friedman, 1992). In terms of potency at the cyclase, SKF75670 and SKF85174 are more potent than SKF38393. Although all D1-agonists enabled reproductive behavior in the present study, the more efficacious SKF85174 proved to be significantly more inhibitory than the less potent, weak agonists SKF38393 and SKF77434. This finding is consistent with previous studies (Everitt et al., 1975; Foreman and Moss, 1979; Grierson et al., 1988) in which the effects of SKF38393 were reported. Interestingly, animals treated with SKF75670, a D1-like agonist with little if any cyclase activity in rat striatal tissue, displayed stimulation of behavior at all doses. This finding is consistent with the possibility that dual transduction mechanisms may modulate dopaminergic effects on reproductive behavior. Indeed, several drugs associated with in vitro hydrolysis of inositol phospholipids also facilitate lordosis when microinjected in estrogen-primed rats (Kow et al., 1994). Moreover, a novel D5 dopamine receptor has been associated with the phosphoinositol second messenger pathway (Mahan et al., 1990). Certainly, additional studies are warranted to clarify the role of second messengers mediating dopaminergic modulation of sex behavior.

The functional and biochemical consequences of D1-like heterogeneity are difficult to assess, because no subtype-selective agonists or antagonists yet exist. However, antisense oligonucleotides for sequence-specific inhibition of gene expression are effective for studying the biological effects of specific proteins (Cohen, 1989; Boixiau et al., 1992). Antisense to D5 dopamine receptor mRNA suppressed induction of lordosis by D1-like agonists, whereas D1 antisense and random sequence oligonucleotides for both the D1 and D5 receptor mRNA had no effect on induction of lordosis by D1-like challenge. These findings implicate the D5 dopamine receptor in the dopaminergic modulation of reproductive behavior. Specificity for the D1 oligonucleotide was confirmed in separate experiments in which animals treated with D1 antisense mimicked the phenotypic behavior pattern associated with D1-deficient mice (Xu et al., 1994). Specifically, antisense to the D1 dopamine receptor mRNA induced high levels of basal activity and inhibited further augmentation of hyperactivity by D1-like stimulation. Further, animals receiving random sense treatment mimicked the wild-type mice, a behavioral pattern requiring intact, functional D1 dopamine receptors (Xu et al., 1994). In addition, animals administered only D1 


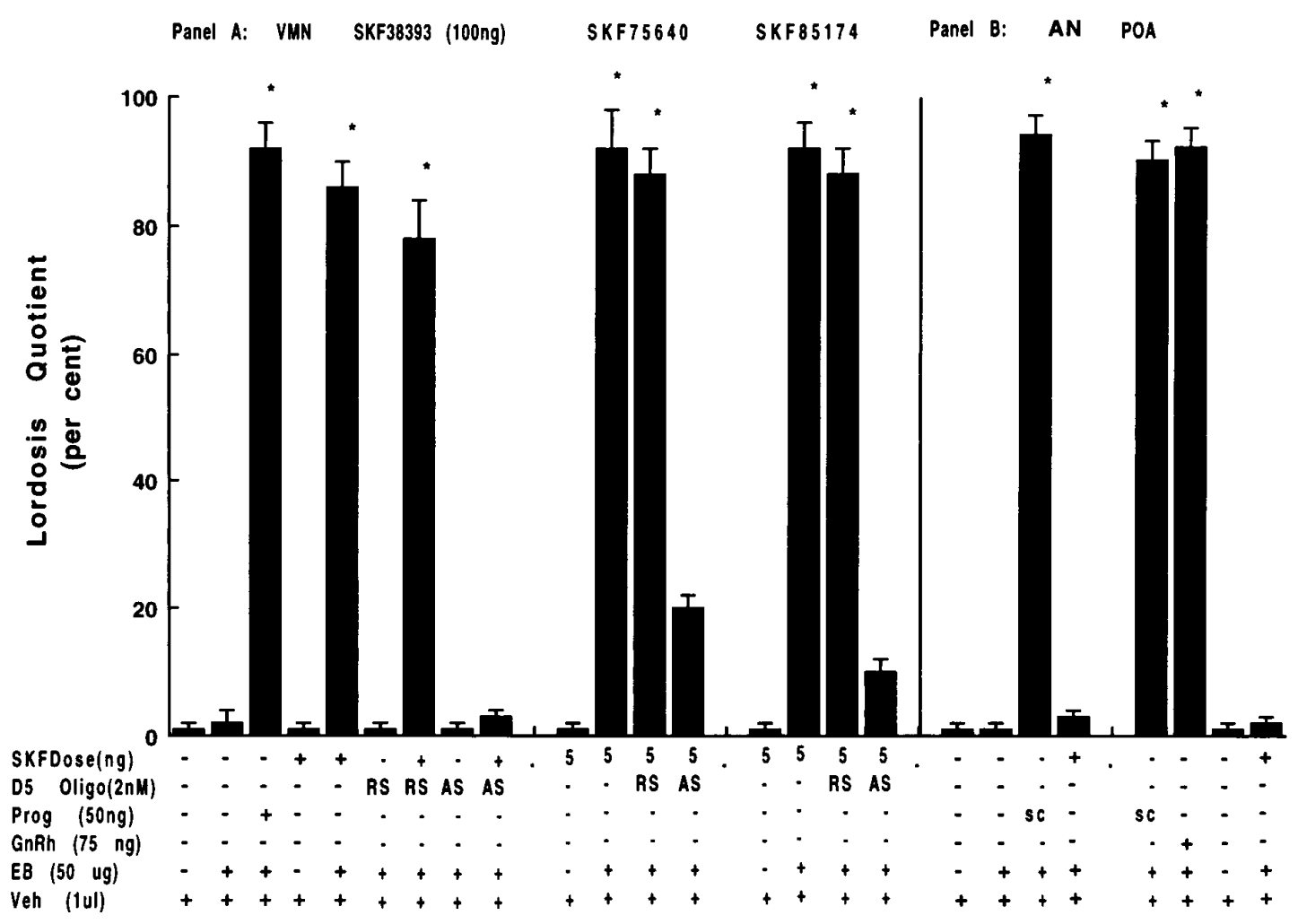

Figure 6. Facilitation of lordosis by microinjections of D1-like agonists into stereotaxically implanted cannulae in the ventromedial nucleus (VMN) $($ Panel $A)$, but not arcuate nucleus $(A N)$ ( panel B) or preoptic area $(P O A)$ (panel B). Fourteen days after screening for false-positive and false-negative behaviors, animals were tested for behavioral responsiveness to SKF38393, SKF75640, or SKF85174. For blockade, D5 antisense oligonucleotide (2 nM total) was injected into VMN cannulae $24 \mathrm{hr}$ before SKF38393 challenge. $B$ presents the responses of those animals with either AN or POA cannulae. Animals served as their own controls for experimental results. Because all responded with LQ above 85\%, the data are not shown from another group of animals with third ventricle cannulas that served to verify the effectiveness of D1-like agonists to induce responses on the day of intranuclear injections. Each experiment was repeated two to three times. Cannula placement was verified by microscopic examination at the end of experimentation. Data are shown for those animals with both cannula tips in target area.

antisense exhibited sex behavior when challenged with D1-like agonists, suggesting also that nonspecific toxicity was not present. Taken together, the data confirm D1 oligo specificity for D1 dopamine receptor-mediated events. Specificity of D5 antisense for D5 dopamine receptor-mediated gene expression was determined by target gene transactivation studies in mouse L(tk-) fibroblast cells stably expressing D5, but not D1, receptors. All in all, the present results provide strong evidence for D5 dopamine receptor-specific mediation of reproductive behavior and represent the first behavior paradigm ostensibly associated with the newly characterized D5 dopamine receptor.

Using in situ hybridization, mRNAs for D1, but not D5, dopamine receptors are demonstrated in the VMN of EBprimed ovariectomized rats in the present study, a finding consistent with previous studies of male rats (Mansour et al., 1992). It is possible that D5 receptors are functionally present, but mRNA is not detectable using current methods. Mechanisms regulating cellular protein levels are unknown for D5 dopamine receptors. In fact, discordant rates of gene transcription and differential mRNA half-lives have been suggested for dopamine receptors (Fox et al., 1993). Moreover, mRNA probes label cell bodies rather than dendritic processes, although ribosomes are clearly present in dendrites (Phillips et al., 1987). Thus, labeling low abundant RNAs may not be readily distinguishable from background and may account for the absence of D5 dopamine receptor mRNA in the VMN. Further, subcellular distribution of mRNAs is not uniform in neurons (Steward and Banker, 1992). Indeed, mRNAs for several proteins are selectively targeted to dendrites and synapses for translation in the brain (Strong et al., 1990; Rao and Steward, 1991). Dopamine receptors are found in areas other than somatic membranes by PCR (Mansour et al., 1990) but not in situ hybridization (Tiberi et al., 1991). Indeed, functional presence of D5 dopamine receptors in the VMN is supported by the present finding that several different D1-like agonists induced lordosis, a effect blocked by antisense to D5, but not D1, receptor mRNA.

Finally, the present study confirms the dependence of dopamine-facilitated reproductive behavior on the PR. Regardless of D1-like agonists, the dopaminergic facilitatory effect was blocked by the antiprogestin RU38486 and antisense to PR. The site of influence was determined by direct microinjections of D1-like agonists and antisense oligos into the VMN, AN, and POA. Because the site of dopaminergic influence of PR-mediated events is within the VMN, it is possible that D5 dopamine receptor-mediated stimulation converted PR to an active form within individual neurons through the alternate ligandindependent pathway shown in vitro for PR (and ER) (Tsai and O'Malley, 1994). In transient transfection studies, PR-dependent gene expression was activated by dopamine, 8-bromo-cAMP, and 


\section{D1 mRNA}

A
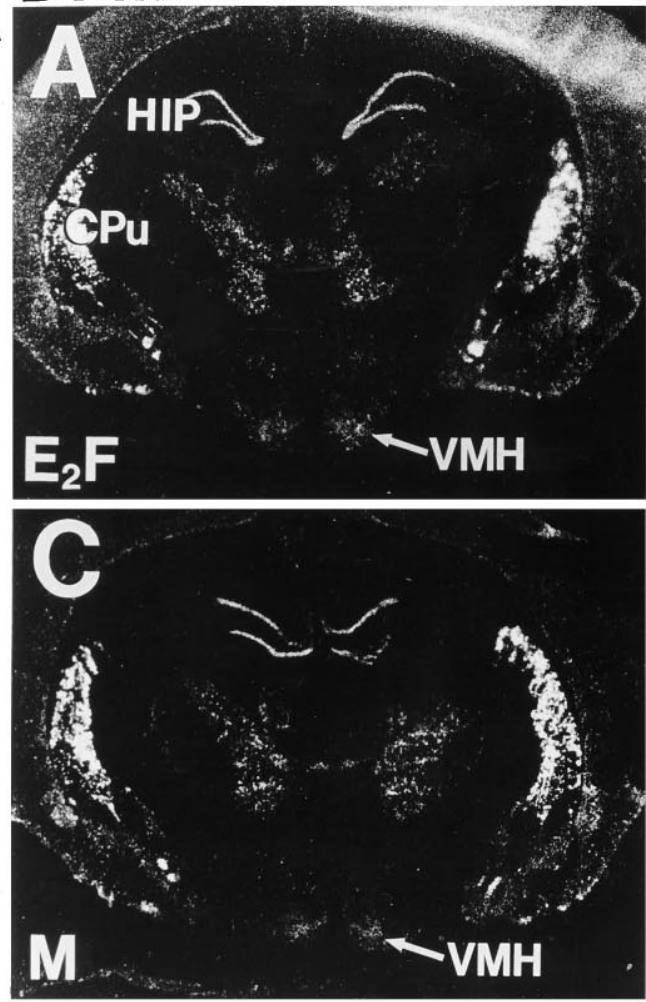

\section{D5 mRNA}

B
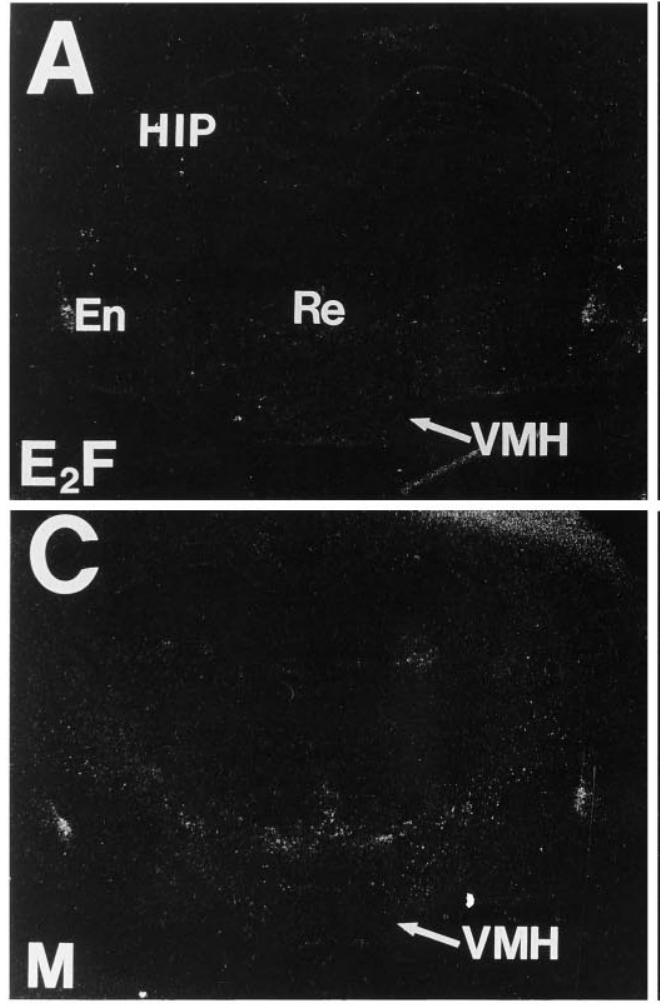

\section{Bregma -3.30}
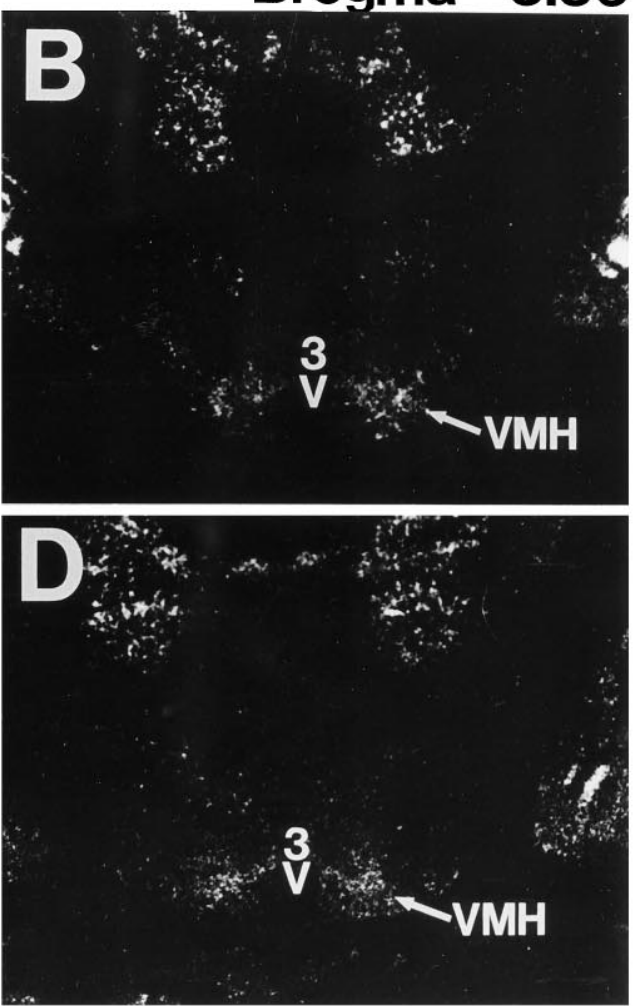

Bregma -3.30

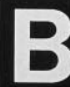

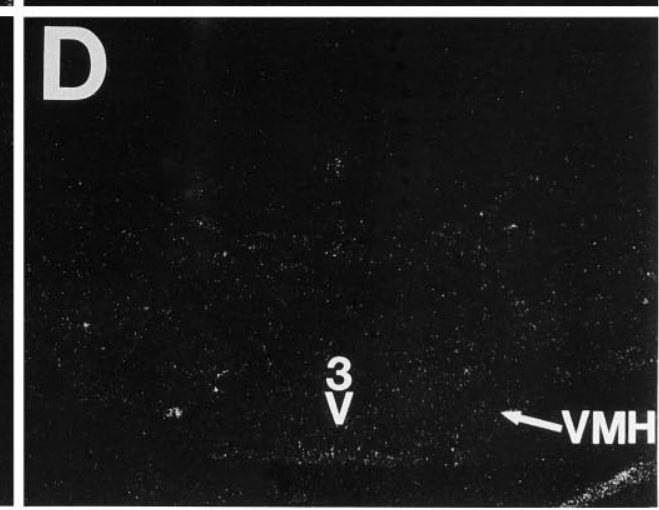

Figure 7. In situ hybridizations and dark-field autoradiograms of D1 $(A)$ and D5 $(B)$ mRNA. Modest distribution of D1, but not D5, dopamine receptor mRNA is visualized in the ventromedial nucleus of the hypothalamus $(V M H) 48 \mathrm{hr}$ after estrogen priming of ovariectomized female $(E 2 F$ in $D 1 A, B ; D 5 A$, $B)$ and in the VMH of male $(M$ in $D 1 C, D ; D 5 C, D)$ rats. A D1 dopamine receptor cRNA probe transcribed from a rat D1 dopamine receptor cDNA and a D5 dopamine receptor riboprobe generated from a partial rat D5 dopamine receptor cDNA were used. $A$ and $C$ are at low magnification, and $B$ and $D$ are at higher magnification. $H I P$, Hippocampus; $C P u$, caudate putamen; $3 V$, third ventricle; Re, reuniens thalamic nucleus; En, endopiriform nucleus. 
the phosphatase inhibitor okadaic acid in the absence of $\mathrm{P}$ (Tsai and O'Malley, 1994). Mutation of a potential PKA phosphorylation site in the PR blocked the effect of dopamine but not P. Collectively, the present in vivo data support the hypothesis that activation of D5 dopaminergic receptors in the VMN alters steroid-dependent behavior through PR-mediated gene expression.

Alternately, modulation of the lordosis reflex could be attributable to local interneuron circuitry. Execution of lordosis is dependent on VMN projections to periaqueductal gray and subject to modulation by neurons in the POA and AN (Pfaff and Schwartz-Giblin, 1988). Fibers from the ventrolateral VMN project extensively to regions that express D5 receptor mRNA in somatic bodies (Meador-Woodruff et al., 1992; Cauteras et al., 1994). Likewise, dopaminergic A13 projections may terminate in the VMN, because microinjections of D1-like agonists into this region facilitate lordosis, a response blocked by local pretreatment with D1-like blockade. Thus, it is plausible that neurons expressing D1-like dopamine receptors exert influence over the transmission of information generated by neurons expressing PR. Further, the present antisense data implicate the D5 dopamine receptor as the responsible D1-like subtype. Moreover, a reciprocal relationship may exist between neurons expressing D5 dopamine receptor and $\mathrm{PR}$, because $\mathrm{P}$ stimulates the release of dopamine (Dluzen and Ramirez, 1989b), an effect inhibited by interneuron blockade (Dluzen and Ramiriz, 1989a). Thus, neuronal circuitry is not ruled out as an explanation for dopaminergic activation of PR-dependent reproductive behavior.

In conclusion, four D1-like agonists mimic $\mathrm{P}$ and facilitate induction of reproductive behavior in EB-primed ovariectomized rats. The D1-like antagonist SCH23390 and, specifically, D5, but not D1, antisense attenuate facilitation of lordosis by D1-like agonists. Dopaminergic stimulation of the VMN, but not AN or POA, was critical for regulation of estrogendependent behavior. Although not detectable by in situ hybridization, the ability of VMN microinjections of D5 antisense block the induction of reproductive behavior by D1-like agonists suggests the functional presence of D5 dopamine receptors in the VMN. The data provide strong evidence for PRdependence of dopamine-induced lordosis, because pretreatment with either PR antisense or antiprogestin RU38486 blocked the effect of D1-like agonists. Taken together, the data support the hypothesis that activation of dopaminergic pathways can modulate reproductive behavior by activation of the PRs in the absence of its cognate ligand.

\section{REFERENCES}

Andersen PH, Jansen JA (1990) Dopamine receptor agonists: selectivity and dopamine D1 receptor efficacy. Eur J Pharmacol Mol Pharmacol Sect 188:335-347.

Boiziau C, Thuong NT, Toulme J-J (1992) Mechanisms of the inhibition of reverse transcription by antisense oligonucleotides. Proc Natl Acad Sci USA 89:768-772.

Cauteras NS, Simerly RB, Swanson LW (1994) Organization of projections from the ventromedial nucleus of the hypothalamus: a phaseolus vulgaris-Leucoagglutinin study in the rat. J Comp Neurol 348:41-79.

Cohen JS (1989) Oligodeoxyribonucleotides. Antisense inhibitors of gene expression. In: Topics in molecular and structural biology, Vol 12 (Cohen JS, ed), pp 1-215. London: Macmillan.

Cristiano RJ, Smith LC, Woo SLC (1993) Hepatic gene therapy: adenovirus enhancement of receptor-mediated gene delivery and expression in primary hepatocytes. Proc Natl Acad Sci USA 90:2122-2126.

Dluzen DE, Ramirez VD (1989a) Progesterone effects upon dopamine release from the corpus striatum of female rats. I. Evidence for a membrane-bound progesterone receptor. Brain Res 476:332-337.
Dluzen DE, Ramirez VD (1989b) Progesterone effects upon dopamine release from the corpus striatum of female rats. II. Evidence for a membrane site of action and the role of albumin. Brain Res 476:338-344.

Dreher JK, Jackson DM (1989) Role of D1 and D2 dopamine receptors in mediating locomotor activity elicited from the nucleus accumbens of rats. Brain Res 487:267-277.

Ehlrich G, Patinkin D, Ginzberg D, Zakut H, Eckstein F, Soreq H (1994) Use of partially phosphorothioated "antisense" oligodeoxynucleotides for sequence-dependent modulation of hematopoiesis in culture. Antisense Res Dev 4:173-183.

Etgin AA (1990) Intrahypothalamic implants of noradrenergic antagonists disrupt lordosis behavior in female rats. Physiol Behav 48:31-36.

Evans RM (1988) The steroid and thyroid hormone receptor superfamily. Science 240:889-895.

Everitt BJ, Fuxe K (1977) Dopamine and sexual behaviour in female rats. Effect of dopamine receptor agonists and sulpride. Neurosci Lett 4:209-213.

Everitt BJ, Fuxe K, Hokfelt T, Jonsson G (1975) Pharmalogical and biochemical studies on the role of monoamines in the control by hormones of sexual receptivity in the female rat. J Comp Physiol Psychol 89:556-572.

Foreman M, Moss R (1979) Role of hypothalamic dopaminergic receptors in the control of lordosis behavior in the female rat. Physiol Behav 22:283-289.

Fox CA, Mansour A, Thompson RC, Bunzow JR, Civelli O, Watson SJ (1993) The distribution of dopamine D2 receptor heteronuclear RNA (hnRNA) in the rat brain. J Chem Neuroanat 6:363-373.

Fox CA, Mansour A, Watson SJ (1994) The effects of haloperidol on dopamine receptor gene expression. Exp Neurol 130:1-16.

Grierson JP, James MD, Pearson JR, Wilson CA (1988) The effect of selective D1 and D2 dopaminergic agents on sexual receptivity in the female rat. Neuropharmacology 27:181-189.

Kow L-M, Mobbs CV, Pfaff DW (1994) Roles of second-messenger systems and neuronal activity in the regulation of lordosis by neurotransmitters, neuropeptides, and estrogen: a review. Neurosci Biobehav Rev 18:251-268.

Mahan LC, Burch RM, Monsma Jr FJ, Sibley DR (1990) Expression of striatal D1 dopamine receptors coupled to inositol phosphate production and $\mathrm{Ca}^{2+}$ mobilization in Xenopus oocytes. Proc Natl Acad Sci USA 87:2196-2200.

Mani SK, Allen JMC, Blaustein Clark JH, O'Malley BW (1994) Convergent pathways for steroid hormone- and neurotransmitter-induced rat sexual behavior. Science 265:1246-1249.

Mansour A, Meador-Woodruff JH, Bunzow JR, Civelli O, Akil H, Watson SJ (1990) Localization of dopamine D2 receptor mRNA and D1 and D2 receptor binding in the rat brain and pituitary: an in situ hybridization-receptor autoradiographic analysis. J Neurosci 10:2587-2600.

Mansour A, Meador-Woodruff JH, Zhou Q, Civelli O, Akil H, Watson SJ (1992) A comparison of D1 receptor binding and mRNA in rat brain using receptor autoradiographic and in situ hybridization techniques. Neuroscience 46:959-971.

McCarthy MM, Brooks PJ, Pfaus JG, Brown HE, Flanagan LM, SchwartzGiblin S, Pfaff DW (1993) Antisense oligonucleotides in behavioral neuroscience. Neuroprotocols 2:67-74.

Meador-Woodruff JH, Mansour A, Grandy DK, Damask SP, Civelli O, Watson SJ (1992) Distribution of D5 dopamine receptor mRNA in rat brain. Neurosci Lett 145:209-212.

O'Boyle KM, Gaitanopoulos DE, Brenner M, Waddington JL (1989) Agonist and antagonist properties of benzazepine and thienopyridine derivatives at the D1 dopamine receptor. Neuropharmacology 28:401-405.

Paxinos G, Watson C (1988) The rat brain in stereotaxic coordinates. New York: Academic.

Pfaff DW, Schwartz-Giblin S (1988) Cellular mechanisms of female reproductive behaviors. In: The physiology of reproduction, Vol 2 (Knobil E, Neill JD, Ewing LL, Greenwald GS, Markert CL, Pfaff DW, eds), pp 1487-1568. New York: Raven.

Phillips LL, Nostrandt SJ, Chikaraishi DM, Steward O (1987) Increases in ribosomal RNA within the denervated neurophil of the dentate gyrus during reinnervation: evaluation by in situ hybridization using DNA probes complementary to ribosomal RNA. Mol Brain Res 2:251-261. 
Pollio G, Xue P, Zanisi M, Nicolin A, Maggi A (1993) Antisense oligonucleotide blocks progesterone-induced lordosis behavior in ovariectomized rats. Mol Brain Res 19:135-139.

Rao A, Steward O (1991) Evidence that protein constituents of postsynaptic membrane specializations are locally synthesized: analysis of proteins synthesized within synaptosomes. J Neurosci 11:2881-2895.

Smith CL, Conneely OM, O'Malley BW (1993) Modulation of the ligand-independent activation of the human estrogen receptor by hormone and antihormone. Proc Natl Acad Sci USA 90:6120-6124.

Steward O, Banker GA (1992) Getting the message from the gene to the synapse: sorting and intracellular transport of RNA in neurons. Trends Neurosci 15:180-185.

Strong MJ, Svedmyr A, Gajdusek DC, Garruto RM (1990) The temporal expression of amyloid precursor protein mRNA in vitro in dissociated hippocampal neuron cultures. Exp Neurol 109:171-179.

Tiberi M, Jarvio KR, Slivia C, Falardeau P, Gingrich JA, Godinot N, Bertrand L, Yang-Feng TL, Fremeau Jr RT, Caron MG (1991)
Cloning, molecular characterization, and chromosomal assignment of a gene encoding a second D-1 dopamine receptor subtype: differential expression pattern in rat brain compared with the D1 $\alpha$ receptor. Proc Natl Acad Sci USA 88:7491-7495.

Tsai M-J, O'Malley BW (1994) Molecular mechanisms of action of steroid/thyroid receptor superfamily members. Annu Rev Biochem 63:451-486.

Undie AS, Friedman E (1992) Selective dopaminergic mechanism of dopamine and SKF38393 stimulation of inositol phosphate formation in rat brain. Eur J Pharmacol Mol Pharmacol Sect 226:297-302.

Xu M, Morstall R, Gold LH, Hirol N, Koob GF, Graybiel Tonegawa S (1994) Dopamine D1 receptor mutant mice are deficient in striatal expression of dynorphin and in dopamine-mediated behavioral responses. Cell 79:729-742.

Zhou Q-Y, Grandy DK, Thambi L, Kushner JA, Van Tol HHM, Cone R, Pribhow D, Salon J, Bunzow JR, Civelli O (1990) Cloning and expression of human and rat D1 dopamine receptors. Nature 347:76-79. 